\title{
Application of blended teaching in public elective courses of design class
}

\author{
Hui Liu* , Haidi He, Chunhong Zhang, and Shan Xu \\ University of Electronic Science and Technology of China, Zhongshan Institution, Zhongshan, \\ Guangdong, China
}

\begin{abstract}
The development of education informatization has brought opportunities for teaching reform in colleges and universities, but there are still some shortcomings when applied to public elective courses (PEC). The Blended Teaching mode that combines the advantages of MOOC and SPOC teaching provides a new exploration for improving the teaching effect of public elective courses. This article relies on the "Everybody Loves Design" MOOC national boutique online open course of Chinese universities, and applies the Blended Teaching model to the teaching of "Industrial Design History" course, a PEC in Z colleges and universities. A teaching model including the selection of course teaching platform and teaching resources, teaching implementation, teaching effect evaluation, teaching reflection, etc was constructed. The results show that this model has a positive effect on improving students' learning interest, learning autonomy and learning effect.
\end{abstract}

Keywords: Industrial design history, Blended teaching, MOOC.

\section{Introduction}

Public Elective Courses(PECs) are quality general education courses offered by universities for all majors and all grades of students, and chosen by students independently ${ }^{[1]}$. They break down the barriers between disciplines, help optimize students' knowledge structure and meet the needs of training composite talents. However, the teaching quality has been frequently questioned, and they have become the hardest hit area of "water courses"[2]. With the development of education informatization, Massive Open Online Course (MOOC), with its rich and high-quality course resources, open course content, short and concise teaching videos and complete course structure ${ }^{[3]}$, has brought opportunities for the teaching reform of PECs.but its shortcomings have gradually emerged. MOOC faces a large number of students, lacks effective supervision, requires students to have strong self-control and self-learning ability, and has certain limitations on practical courses ${ }^{[4]}$. Subsequently, studies in the United States and Japan have found that the Blended Teaching Model(BTM) is better than traditional classroom teaching and complete online learning ${ }^{[5]}$. In the "Guiding Opinions on Deepening Education and Teaching

*Corresponding author: 23858742@.qq.com 
Reforms in Universities Under the Central Government" issued by the Ministry of Education in 2016, "promote inter-school online and offline hybrid teaching reforms" [1]. This article takes the public elective course "Industrial Design History" ,one of the PECs offered by University $\mathrm{Z}$ as an example, and relies on the Chinese University MOOC National Excellence Online Open Course "Everyone Loves Design" to verify the feasibility of BTM in the public elective courses of design class.

\section{Blended teaching}

Blended Teaching (BT) is a product of the integration of modern information technology and education. It adopts both "online" and "offline" methods to carry out teaching.Course content is pushed to students for self-study or pre-study in the form of videos, questions or PPT before class; Offline classroom lectures on the difficulties and key points; supplementary materials and coursework are sent after class to consolidate knowledge [5].Under the traditional teaching mode, teachers often find it difficult to control the learning process of students, while various teaching platforms can make comprehensive use of digital information technology such as statistics, information visualisation and big data to track students' learning process in real time.BT combines the advantages of the two teaching modes to the greatest extent. It can not only play the leading role of teachers in guiding, enlightening, and monitoring the teaching process, but also fully reflect the initiative, enthusiasm and creativity of students as the main body of the learning process ${ }^{[6]}$.

\section{Course characteristics and significance}

The "Industrial Design History" is an PEC that focuses on the evolution of design styles,design genres and the historical background of their occurrence since the Industrial Revolution. For non-design students, through this course, they can be familiar with the development and evolution of industrial design, draw on historical experience, integrate their own professional backgrounds, realize the internalization of design thinking, and inspire their observation, analysis, creation and independent thinking capabilities. In order to realize "Created in China", it cultivates design and innovative thinking, which is consistent with the teaching goal of the Chinese University MOOC "Everyone loves design", so it is very suitable for opening to the whole school.

\section{Implementation of BT}

\subsection{Teaching platform and teaching resources}

\subsubsection{Teaching platform}

The teaching resource platform and the course interaction platform are "China University MOOC" and "Chaoxing Fanya" SPOC module respectively. "Everyone Loves Design" is the first batch of national high-quality online open courses built on the basis of the China University MOOC. Chaoxing Fanya is an online teaching platform that integrates teaching interaction, resource management, teaching management evaluation and teaching results display. Teachers can use the platform to achieve class construction, teaching task release and teaching resource sharing before class. They can also realize full teaching interaction and classroom management on the platform. After class, teachers can also post homework, 
answer questions online, and display homework on the platform. It can accurately record and analyze teacher teaching and student learning, so as to form teaching big data, which will help teachers master the learning process.

\subsubsection{Teaching resources}

The teaching resources used in the course are mainly based on the teaching videos and post-lesson discussions of the MOOC "Everybody Loves Design" (taught by Professor Wang Zhenya from Shandong University), while the course unit assignments and accompanying tests are adjusted according to the professional background of the students taking the course. Given that the length of the MOOC videos is usually about 10 minutes ${ }^{[7]}$ and the knowledge is "fragmented"[8], seven e-books including “ Modern World History" and related videos were added to the Chaoxing Fanya platform as a supplement to the MOOC course in order to help non-design students form a systematic knowledge chain about design theory.

\subsection{Teaching process design}

\subsubsection{Establish curriculum resources}

According to the characteristics and needs of the students who choose this course, a total of 16 knowledge points from the first and second phases of "Everybody Loves Design" are integrated into 32 class hours of teaching resources in one semester. Teachers announce their learning goals, courseware and auxiliary teaching resources in advance on the Superstar Fanya platform, and use the class management function of the Fanya platform to release learning tasks in a timely manner. In addition, Wechat groups and curriculum discussion areas for teaching communication are established to collect students' learning feedback and share design cases, making it a beneficial extension of classroom teaching and realizing the purpose of "sharing learning" [9].

\subsubsection{Study situation analysis before class}

To a certain extent, teaching design comes from the cognition of students ${ }^{[10]}$.In order to fully understand students' professional background, cognition of design, motivation of course selection and learning expectation, so as to teach students in accordance with their aptitude, a learning situation survey is carried out before the start of the course. The survey results show that the elective students include most of the liberal arts and sciences such as journalism, financial management, software engineering, and applied chemistry. $30 \%$ of the students were forced to choose this course because they "didn't choose the ideal course." $27 \%$ of the students said they were "interested in design".How to combine students' diverse professional backgrounds with design professional knowledge to plan classroom content and teaching practice tasks and stimulate learning enthusiasm is the entry point to ensure teaching effectiveness.

\subsubsection{Teaching implementation}

Online teaching is mainly based on students' self-study curriculum videos and completing after-class discussions or chapter tests; offline teaching is mainly based on guided, heuristic, 
and case-based teaching methods, supplemented by group discussions, design practice guidance, design work display and comment.

\subsubsection{Students study independently.}

Teachers release teaching plans and learning tasks in advance, and students learn online teaching videos independently according to requirements.At the same time, teachers use real-time big data of the platform to monitor students' online learning progress, guide learning and answer questions in the class Wechat group, so they can record common problems in the process of independent learning and form the focus of offline teaching.

\subsubsection{Learning test}

In order to test the effect of students' online self-study, the Fanya platform will be used to publish test questions before the start of offline teaching. So the students are "forced" to learn key knowledge repeatedly and strengthen memory and understanding. For the knowledge points with a high error rate, the teacher supplements learning materials, focusing on the explanation. For example, after learning the first chapter "What is design" video, $53 \%$ of students still cannot distinguish between design and art. The clarity of these two concepts is the basis for subsequent learning. Therefore, the offline class is focused on explaining this by combining theories and design examples. Pre-class learning detection is a feedback on the effect of students' self-study. The most important thing is that it helps teachers to further clarify the focus of teaching in a targeted manner.

\subsubsection{Internalization of knowledge}

"Learning before teaching" [11] is one of the advantages of BT. Students have mastered most of the theoretical knowledge through online videos, so teachers will use case-based and heuristic teaching methods to increase the depth of design case explanation to make up for the deficiency of video teaching and promote the internalization of knowledge in the offline classroom. For example, in order to distinguish the relationship between design and art, the offline classes focus on explaining and illustrating by comparing typical design works and art works, and adding short videos such as "The relationship between design and art" and "Learning design is learning software" on the Fanya platform. Through pre-class tests and analysis, it was found that $88 \%$ of students had "heard of design but did not understand the socio-economic benefits it can bring". In response to this, the topic of "Industrial Design for Made in China 2025" was added, which is not covered in the MOOC videos.

\subsubsection{Course design}

In the course design process, a step-by-step design thinking process of "free proposition semi-free proposition - prescribed proposition" is followed. For example, in the early stage of teaching, students are asked to break their fixed mindset to think about and answer "what are your whimsical ideas that can be transformed into products to improve our lives?". After in-depth study, students are required to "combine their professional backgrounds, and based on full research, to improve the design of products. "All design works are displayed online and students comment on each other's works. In offline classrooms, teachers analyze the pros and cons of the works. In this process, the innovative methods of design are communicated to the students, avoiding the disconnection between theoretical knowledge 
and design practice. Learning by doing, doing while learning, is more suitable for the teaching of design public elective courses.

\subsubsection{Feedback after class}

Teaching informatization realizes real-time teaching process feedback. Teachers can not only dig into students' learning process data such as the number and length of videos watched etc., but can also summarize and analyse problems students encountered. Questions and students' suggestions will be fed back to the online platform in time, and improvements will be made in the next class to achieve "learning for each other" and improve the quality of teaching.

\subsection{Evaluation and reflection on teaching effect}

\subsubsection{Comparative analysis of the effects of traditional teaching and BT}

The BT practice, which lasted for two semesters, was compared with the traditional teaching in the past, and it was found that the students who took the course had basically the same major background, covering most of the arts and science majors in the university, but there was a big difference in students' attendance, final grades and satisfaction with the teaching.

Under the traditional teaching model, the attendance rate of the course shows a trend of $100 \%$ attendance in the first class and decreasing in subsequent classes, with the average attendance rate remaining at around $88 \%$ and some students failing the course due to persistent absenteeism and failure to submit assignments. However, in the blended mode of teaching, $100 \%$ of the students can complete the online video learning, the average attendance in the offline classes is $98 \%$, and the completion rate of the quizzes and post-class assignments is $100 \%$.

Table 1 shows the final semester grades for Fall 2020 ( BT was used) and Fall 2019 (traditional teaching was used), from which it can be seen that the average grade of BT classes is 11 points higher than that of traditional teaching classes, and the merit rate $(5 \%)$ is also $40 \%$ higher, while the failure rate is also reduced by $23.2 \%$. This shows that the BT mode can greatly enhance students' interest in learning and learning effectiveness, and the teaching effect is better.

Table 1. Comparison of learning effectiveness between BT and traditional teaching.

\begin{tabular}{|c|c|c|c|c|c|}
\hline \multicolumn{6}{|c|}{$\begin{array}{l}\text { Fall } 2020 \text { ( BT was used) } 65 \text { students, the highest score is } 90 \text {, the lowest score is } 68 \text {, the average } \\
\text { score is } 79.8\end{array}$} \\
\hline Scores Range & $100-90$ & $89-80$ & $79-70$ & $69-60$ & $<60$ \\
\hline Number of Students & 5 & 26 & 31 & 3 & 0 \\
\hline Proportion & $7.7 \%$ & $40 \%$ & $47.7 \%$ & $4.6 \%$ & $0 \%$ \\
\hline
\end{tabular}

Fall 2019 (traditional teaching was used) 69 students, the highest score is 88 , the lowest score is 39, the average score is 68.9

\begin{tabular}{cccccc}
\hline Scores Range & $100-90$ & $89-80$ & $79-70$ & $69-60$ & $<60$ \\
Number of Students & 2 & 20 & 10 & 21 & 16 \\
Proportion & $2.9 \%$ & $29 \%$ & $14.5 \%$ & $30.4 \%$ & $23.2 \%$ \\
\hline
\end{tabular}

The survey on the satisfaction of teaching resources, knowledge mastery, motivation of learning initiative and teaching satisfaction shows that $83.7 \%$ of students prefer the BT 
method. $89.8 \%$ of the students are satisfied with the MOOC teaching videos and the teaching resources supplemented by Chaoxing Fanya platform, because it expands the breadth and depth of knowledge. $75.8 \%$ of students felt that the blended approach of pre-class preview, key explanation in class and interactive question-and-answer after class helped to motivate learning. The BT has effectively improved learning and achieved the desired teaching effect.

\subsubsection{Teaching reflection}

$\mathrm{BT}$ is conducive to teachers making full use of the national excellent teaching resources, combining the school's teaching practice and student needs, making appropriate adjustments and supplements, so that students can participate in deep and meaningful learning.

BT breaks the constraints of teaching time and space, and breaks the shackles of teacher-student identity. Students are the masters of the classroom, while teachers are the guides and supporters. For design PEC, it is worthwhile for every professional teacher of design major to further explore how to choose teaching resources and educational methods, and how to let design thinking penetrate into the existing professional background of non-design students.

\section{Summary}

Design courses require a close integration of design theory and design practice, as a PEC, a semester of 32 hours of class time cannot achieve a comprehensive and in-depth training of students' design thinking and innovative ability. The National MOOC provides a good foundation for the development of design public courses. Under BT method, students study online videos on their own and teachers explain key points in the offline classroom, which allows more classroom time to be allocated to case studies and product innovation design practice, strengthening students' knowledge of design. In this paper, the application of BT to the public elective course "History of Industrial Design" shows that BT method has a positive effect on enhancing students' learning interest, learning autonomy and learning effectiveness.

This article is supported by the first Blended Teaching model reform project "'Everyone loves design' Blended Teaching model reform" (No.hhkc201024) of University of Electronic Science and Technology of China, Zhongshan Institution in 2020.

\section{References}

1. Lin Tong. Problems in university public elective courses and ways to improve teaching quality[J]. Journal of Southwest China Normal University (Natural Science Edition), 2015, 40(07): p.194.

2. Hu Xiaoping. Research on the Construction of Quality Assurance Mechanism for Public Elective Courses in Chinese Universities-Taking Universities in Province G as an Example [J]. Education and Examination, 2021, (01): p.84.

3. Li Yanqi, Zhao Huichen. The influence of MOOC on traditional classroom teaching and its countermeasures[J]. Digital Education, 2015, (4): p.15.

4. Zhu Lin, Liu Hongyong. Analysis of the advantages and disadvantages of MOOC education in the Internet education era[J]. Industry and Technology Forum, 2018, 17(02):p. 91. 
5. He Hongyun, Deng Yihao. Preliminary study on the application of hybrid teaching based on "Rain Class" in field anatomy of human anatomy[J]. Basic Medicine and Clinics, 2020, 40(12): p.1751.

6. Looking at the new development of educational technology theory from Blending Learning [J].p.145

7. Ji Quanyan. How to introduce MOOC into independent colleges [J]. Journal of Hubei Open Vocational College, 2019, 32(23): p.136.

8. Li Jianzhong, Yuan Jin. The network response of traditional humanities in the era of "Internet+"-Based on the academic investigation of MOOC in Chinese universities[J]. Journal of China University of Geosciences (Social Science Edition), 2015, 15(06): p.120. 